\title{
Personal Radiation Protection and Corresponding Dosimetry in Interventional Radiology: An Overview and Future Developments
} Persönliche Strahlenschutzmittel und Dosimetrie des medizinischen Personals in der interventionellen Radiologie: Aktueller Status und neue Entwicklungen

Authors

Alexander Marc König ${ }^{1}$, Robin Etzel ${ }^{2}$, Rohit Philip Thomas ${ }^{1}$, Andreas H. Mahnken ${ }^{1}$

Affiliations

1 Diagnostic and Interventional Radiology, Philipps-University Marburg, Germany

2 Institute of Medical Physics and Radiation Protection, Mittelhessen University of Applied Sciences, Giessen, Germany

\section{Key words}

interventional procedures, physics, radiation effects, radiation safety, safety

received 09.02 .2018

accepted 01.11.2018

\section{Bibliography}

DOI https://doi.org/10.1055/a-0800-0113

Published online: 31.1.2019

Fortschr Röntgenstr 2019; 191: 512-521

(c) Georg Thieme Verlag KG, Stuttgart · New York

ISSN 1438-9029

Correspondence

Alexander Marc König

Department of Diagnostic Radiology, Philipps-University

Marburg, Baldingerstrasse, 35043 Marburg, Germany

Tel.: ++49/6421/58/65993

Fax: ++49/64 21/58/68959

AKoenig@med.uni-marburg.de

\section{ABSTRACT}

Background The increasing number of minimally invasive fluoroscopy-guided interventions is likely to result in higher radiation exposure for interventional radiologists and medical staff. Not only the number of procedures but also the complexity of these procedures and therefore the exposure time as well are growing. There are various radiation protection means for protecting medical staff against scatter radiation. This article will provide an overview of the different protection devices, their efficacy in terms of radiation protection and the corresponding dosimetry.

Method The following key words were used to search the literature: radiation protection, eye lens dose, radiation exposure in interventional radiology, cataract, cancer risk, dosimetry in interventional radiology, radiation dosimetry. Results and Conclusion Optimal radiation protection always requires a combination of different radiation protection devices. Radiation protection and monitoring of the head and neck, especially of the eye lenses, is not yet sufficiently accepted and further development is needed in this field. To reduce the risk of cataract, new protection glasses with an integrated dosimeter are to be introduced in clinical routine practice.

Key Points:

- A combination of personal radiation protection devices and optimized dosimetry improves the safety of medical staff.

\section{Citation Format}

- König AM, Etzel R, Thomas RP et al. Personal Radiation Protection and Corresponding Dosimetry in Interventional Radiology: An Overview and Future Developments.

Fortschr Röntgenstr 2019; 191: 512-521

\section{ZUSAMMENFASSUNG}

Hintergrund Röntgenstrahlen haben ein sehr breites Anwendungsspektrum in der Medizin. Mit dem Trend zu minimalinvasiven Eingriffen steigen besonders die Zahlen Computertomografie- (CT) und durchleuchtungsgesteuerter Interventionen. Mit der zunehmenden Komplexität der Eingriffe steigt außerdem die Untersuchungsdauer und damit häufig auch die Expositionsdauer. Um das medizinische Personal vor allem vor der Streustrahlung zu schützen, gibt es eine Vielzahl von persönlichen Strahlenschutzmitteln. Diese Übersichtsarbeit soll einen Überblick über die verfügbaren Systeme, ihre Effektivität bezüglich des persönlichen Strahlenschutzes und der entsprechenden Dosimetrie geben. Methode Literaturrecherche, vor allem in pubmed mit den Schlüsselwörtern: Strahlenschutz, Augenlinsendosis, Strahlenexposition in der interventionellen Radiologie, Katarakt, Tumorrisiko, Dosimetrie in der interventionellen Radiologie und Strahlendosimetrie.

Ergebnisse und Schlussfolgerung Ein optimaler Strahlschutz sieht immer eine Kombination aus unterschiedlichen Strahlenschutzmitteln bzw. Methoden vor. Der Strahlenschutz 
und das Monitoring des Kopf-Hals-Bereichs, vor allem der Augenlinse, hat weiterhin Entwicklungs- und Akzeptanzbedarf. Hier werden neue Bleiglas-Brillen mit integrierten
Dosimetern erwartet, damit zukünftig die genaue Dosis bestimmt und somit das Kataraktrisiko reduziert werden kann.

\section{Introduction/background}

On November 8, 1895, the physicist Wilhelm Conrad Röntgen discovered $X$-rays. The diagnostic and therapeutic possibilities were quickly identified and further developed. The first acute radiation injuries were seen in the year after the discovery of $X$-rays and their initial clinical application, primarily in the form of injury to the skin, such as hair loss and dermatitis. Eye irritation was also reported [1]. The radiation injuries were deterministic in nature, i.e., tissue injury occurred after a threshold dose was exceeded. It was shown for the first time in 1902 that ongoing radiation exposure can cause carcinoma of the skin [2] in the form of a stochastic radiation injury that occurs randomly and is due to a change in DNA. Increasing radiation exposure increases the probability of radiation injury approximately linearly. Radiation dermatitis experienced by radiologists and radiographers due to chronic radiation exposure was reported for the first time in 1904 [3]. The first radiation protection measures in the form of shielding of the X-ray tube were presented in 1898 [4]. The first means of personal radiation protection in the form of protective gloves, lead jackets, beard covers, protective caps, and lead glasses were recommended in 1905 [5]. Leaded protective booths for operating personnel were also constructed. A regulation regarding radiation protection and the corresponding dosimetry was established when the German Radiological Society was founded on May 2, 1905 and was legally adopted the following year. The first general radiation protection recommendations were published by the German Radiological Society in 1913. Radiation protection was further developed in all areas in the following years primarily due to the constantly improving measurement technology and the growing experience, particularly with respect to longterm damage [6].

Today, X-rays have a broad range of applications in medicine. With the trend toward minimally invasive interventions, the number of procedures and, due to increasing complexity, the examination time are increasing particularly with respect to radiological, neuroradiological, cardiological, orthopedic and vascular interventions using X-ray fluoroscopy [7, 8]. Most studies regarding personal radiation protection focus on this area but CT-guided interventions are also increasing in frequency and currently cover a broad application spectrum [9]. This trend also entails an increase in the radiation exposure of medical personnel.

The consequences of long-term exposure to X-rays with a low effective dose is still the subject of current studies and continues to be a topic of controversy. While several current studies were not able to show an increased risk for a malignant disease in radiologic technologists $[10,11]$, other studies show double the risk for a brain tumor and a moderately elevated risk for melanoma and a breast tumor [12]. A much less controversial consequence of long-term radiation exposure is the formation of a cataract.
The results of Seals et al. indicate that cataractogenesis tends to be a stochastic and not a deterministic effect as was long assumed [13].

This was taken into account in the new guidelines of the European Atomic Energy Community (EURATOM) (directive 2013/59/Euratom) and is intended to help further improve medical radiation protection. The new guidelines are to become national law in 2018 and will enter into force on 12/31/2018. The new limit for eye lenses, which was reduced from $150 \mathrm{mSv} / \mathrm{year}$ to $20 \mathrm{mSv} /$ year, is of particular note here. A comparison of the dose limits of the currently valid X-Ray Ordinance and the new Radiation Protection Act is provided in $>$ Table 1.

\section{Radiation protection}

\section{General principles}

The "ALARA" (as low as reasonably achievable) principle, i. e., ionizing radiation must be kept as low as reasonably possible, is a fundamental rule in radiation protection. A further principle of radiation protection is the inverse square law which states that the dose rate per surface area decreases in inverse proportion to the square of the distance. This means that the dose rate is reduced by one-fourth when the distance to the radiation source doubles. For all interventions involving $\mathrm{X}$-rays, it must be ensured that the examiner is not exposed to the primary beam. The majority of an examiner's personal dose is the result of the scatter radiation primarily emitted by the patient ( $\vee$ Fig. 1 ).

Apart from that, radiation protection covers a broad range and can be generally divided into three main categories:

- Equipment-based radiation protection

- Structural radiation protection

- Personal radiation protection

This article is intended to provide an overview ( $\vee$ Table 2 ) of the available means of personal radiation protection, their effectiveness, and a look at new developments and future trends.

\section{Equipment-based radiation protection for medical personnel}

\section{Mobile lead glass screen}

Lead glass screens have different shapes depending on their intended use and are usually made of acrylic glass and lead oxide. They usually have a lead equivalent of $0.5 \mathrm{~mm}$. This means that the acrylic glass screen in connection with the lead oxide blocks $X$-rays as well as lead shielding with a thickness of $0.5 \mathrm{~mm}$. Such a mobile, usually ceiling-mounted, lead glass screen ( $\triangleright$ Fig. 2), 
- Table 1 Comparison of the occupational dose values of the "X-Ray Ordinance" and the new "Radiation Protection Act" of category A.

\begin{tabular}{|c|c|c|}
\hline & X-ray ordinance, limit value & new radiation protection act, limit value \\
\hline total body dose & $\begin{array}{l}20 \mathrm{mSv} \text { per year } \\
\text { exception: } \\
50 \mathrm{mSv} \text { per year (in } 5 \text { successive years not } \\
>100 \mathrm{mSv} \text { ) }\end{array}$ & $\begin{array}{l}20 \mathrm{mSv} \text { per year } \\
\text { exception: } \\
50 \mathrm{mSv} \text { per year (in } 5 \text { successive years not } \\
>100 \mathrm{mSv} \text { ) }\end{array}$ \\
\hline eye lens & 150 mSv per year & 20 mSv per year \\
\hline local skin dose & $500 \mathrm{mSv}$ per year & $\begin{array}{l}500 \mathrm{mSv} \text { per year (averaged over any skin surface } \\
\text { of one square centimeter) }\end{array}$ \\
\hline hands, lower arms, feet, ankles & $500 \mathrm{mSv}$ per year & $500 \mathrm{mSv}$ per year \\
\hline gonads, uterus, bone marrow & $50 \mathrm{mSv}$ per year & no longer specified \\
\hline thyroid, bone surface & $300 \mathrm{mSv}$ per year & no longer specified \\
\hline $\begin{array}{l}\text { large intestine, lung, stomach, bladder, breast, } \\
\text { liver, esophagus }\end{array}$ & $150 \mathrm{mSv}$ per year & no longer specified \\
\hline $\begin{array}{l}\text { lifetime occupational dose (authorities can } \\
\text { allow additional exposure with written consent } \\
\text { of the person being exposed to radiation) }\end{array}$ & $\begin{array}{l}400 \mathrm{mSv} \\
\text { exception after the lifetime occupational dose has } \\
\text { been reached: maximum additional } 10 \mathrm{mSv} \text { per year }\end{array}$ & $\begin{array}{l}400 \mathrm{mSv} \\
\text { exception after the lifetime occupational dose has } \\
\text { been reached: maximum additional } 10 \mathrm{mSv} \text { per year }\end{array}$ \\
\hline
\end{tabular}
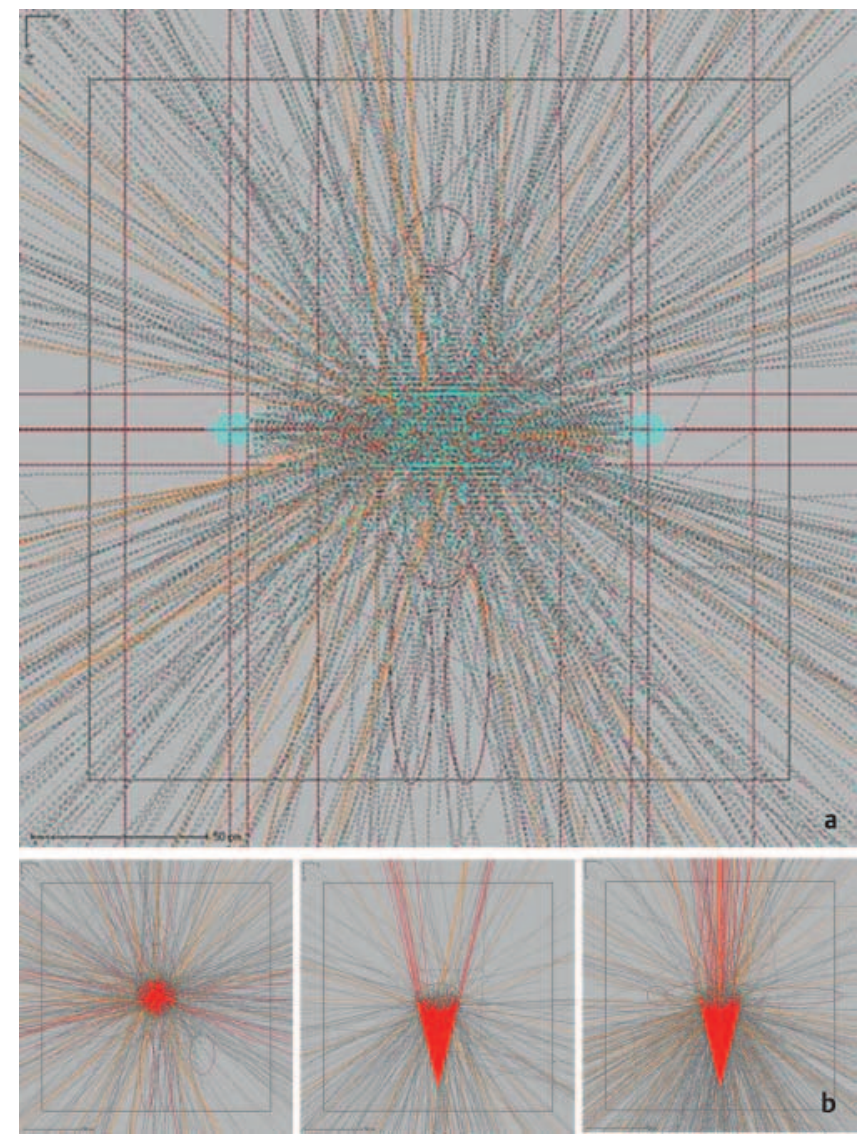

- Fig. 1 a Simulation of scatter radiation during a CT scan (top view). b Simulation of the scatter radiation during a fluoroscopyguided intervention (f.I.t.r: top view, axial view and lateral view). The software EGS-Ray (C. Kleinschmidt, University of Cologne) was used for the simulations with the following main parameters: $80 \mathrm{kV}$ X-ray spectrum (photons); data sets from ICRU report 521. which protects the examiner from additional radiation exposure particularly in the area of the upper body, can achieve a reduction of the local dose of $50-60 \%$ in the region of the head-neck, particularly the eye lenses [14-16]. Depending on the angle of the $\mathrm{X}$-ray tube, the radiation exposure can even be reduced by $90-98 \%$. This is important particularly when the $X$-ray tube is on the same side as the examiner since a high local dose is reached in the region of the examiner's upper body due to the geometry of the scatter radiation. In relation to the eye lenses, a reduction of the local dose of $50.0-96.7 \%$ with exclusive use of the mobile lead glass screen could be shown in phantom experiments and simulations [16-23]. This system can be further improved by enlarging the effective surface of the screen and additionally attaching lead strips to the bottom. In this way Gilligan et al. were able to achieve a reduction of the local dose with respect to the examiner's neck from $15.4 \mu$ Sv to $7.3 \mu$ Sv $(52.6 \%)$ per examination [24].

\section{Under-table shielding}

Shielding attached to the underside of the patient table protects the examiner primarily in the region of the lower extremities ( $\vee$ Fig. 2). This shielding is made either of a continuous material or of strips which ensure better fitting to the examiner. Moreover, the shielding usually extends up beyond the edge of patient table to block scatter radiation emitted laterally by the patient. These materials typically have a lead equivalent of $0.5 \mathrm{~mm}$. Some studies were able to show a reduction of the local dose in the region of the examiner's lower extremities of up to $64 \%$ (from $5.54 \mathrm{mSv}$ to $1.98 \mathrm{mSv}$ on average) $[16,25,26]$.

A reduction in the local dose to the lower extremities of $38.2 \%$ using experimental under-table shielding in interventional CT examinations was also able to be shown [27]. Neeman et al. were able to show that a maximum local dose reduction of $85.6 \%$ for the upper body, $93.3 \%$ (from $25.4 \mu$ Gy to $1.7 \mu$ Gy on average) 
- Table 2 Overview of different radiation protection means and their efficacy.

\begin{tabular}{|c|c|c|c|c|}
\hline & modality & study & body region & dose reduction [\%] \\
\hline \multirow[t]{3}{*}{ mobile lead glass screen } & angiography & $14,15,16$ & head, neck, and eye lens & $50.0-60.0$ \\
\hline & angiography & $\begin{array}{l}16,17,18,19 \\
20,21,22,23\end{array}$ & eye lens & $50.0-96.7$ \\
\hline & angiography & 24 & neck & $52.6(15.4 \mu S v$ to $7.3 \mu S v)$ \\
\hline \multirow[t]{2}{*}{ under-table shielding } & angiography & $16,25,26$ & lower extremities & $64.0(5.54 \mathrm{mSv}$ to $1.98 \mathrm{mSv})$ \\
\hline & computed tomography & 27 & lower extremities & 38.2 \\
\hline \multirow[t]{3}{*}{ + shielding at the gantry } & computed tomography & 28 & upper body & 85.6 \\
\hline & & & gonads & $93.3(25.4 \mu G y$ to $1.7 \mu G y)$ \\
\hline & & & hands & 85.1 \\
\hline \multirow{2}{*}{ mobile radiation protection barrier } & angiography & 15 & abdomen & 96.1 ( $0^{\circ}$ angle) \\
\hline & & & & 88.0 (lateral angle) \\
\hline \multirow[t]{2}{*}{$\begin{array}{l}\text { + radiation protection placed on } \\
\text { the patient }\end{array}$} & & & & 98.9 \\
\hline & computed tomography & 29 & & 84.0 \\
\hline \multirow{4}{*}{$\begin{array}{l}\text { scatter radiation protection } \\
\text { placed on the patient }\end{array}$} & angiography & $16,30,31$ & eye & 91.7 \\
\hline & & & thyroid & 96.0 \\
\hline & & & hands & 96.6 \\
\hline & angiography & 32 & thorax & $56.9(20.9 \mu \mathrm{Sv}$ to $9.0 \mu \mathrm{Sv})$ \\
\hline radiation protection vest & general & 34 & & $\begin{array}{l}80.0 \text { (wraparound apron vs. front } \\
\text { apron) }\end{array}$ \\
\hline \multirow[t]{2}{*}{ thyroid protection } & general & $16,40,41$ & thyroid & 90.7 (alternative materials) \\
\hline & & & & 72.4 (lead-based) \\
\hline $\begin{array}{l}\text { free-hanging radiation protection } \\
\text { system }\end{array}$ & angiography & 44 & head-neck region & $\begin{array}{l}94.0 \text { (in contrast to radiation pro- } \\
\text { tection apron) }\end{array}$ \\
\hline \multirow[t]{2}{*}{ radiation protection glasses } & angiography & $17,18,19$ & eye & $66.7-96.0$ \\
\hline & angiography & 22,46 & eye & 50.0 \\
\hline + mobile lead glass screen & & & & 82.5 \\
\hline lead glass visors & angiography & 17 & eye & $85.0-90.0$ \\
\hline \multirow[t]{2}{*}{ radiation protection cap } & angiography & 40 & head & 85.4 ( $224 \mu \mathrm{Sv}$ to $48 \mu \mathrm{Sv})$ \\
\hline & angiography & 45,46 & head & 3.3 \\
\hline \multirow[t]{2}{*}{ radiation protection gloves } & computed tomography & 28 & hand & 97.1 (1792 $\mu$ Gy to $52 \mu G y)$ \\
\hline & angiography & 48 & hand & 42.6 \\
\hline in the beam path & & 48 & hand & increase to 64.5 \\
\hline
\end{tabular}

for the gonads, and $85.1 \%$ for the hands can be achieved by using shielding in the region of the gantry in addition to the under-table shielding [28].

\section{Mobile radiation protection barrier}

Mobile radiation protection barriers are available in a wide range of sizes, shapes, and designs. They essentially come as half-height barriers that protect the examiner from scatter radiation up to the abdomen and full-size barriers that usually have a window or are made entirely of a transparent material. These mobile radiation protection barriers usually have a lead equivalent of $0.5 \mathrm{~mm}$ and can reduce the dose rate by $96.1 \%$ (converted averages from air kerma: $245.6 \mu \mathrm{Gy} / \mathrm{h}$ to $9.5 \mu \mathrm{Gy} / \mathrm{h}$ ) when an X-ray tube angle of $0^{\circ}$ is used. In the case of lateral angling to the left (X-ray tube on the side facing the measurement chamber), the dose rate reduction is only $88 \%$ (converted averages from air kerma: $160.5 \mu \mathrm{Gy} / \mathrm{h}$ to $19.3 \mu \mathrm{Gy} / \mathrm{h}$ ). If such a mobile radiation protection barrier is combined with radiation protection directly on the patient, the dose rate can even be reduced by up to $98.9 \%$ (converted averages from air kerma: $245.6 \mu \mathrm{Gy} / \mathrm{h}$ to $3 \mu \mathrm{Gy} / \mathrm{h}$ ) [15]. An average dose rate reduction of $84 \%$ can be achieved in CT-guided interventions 

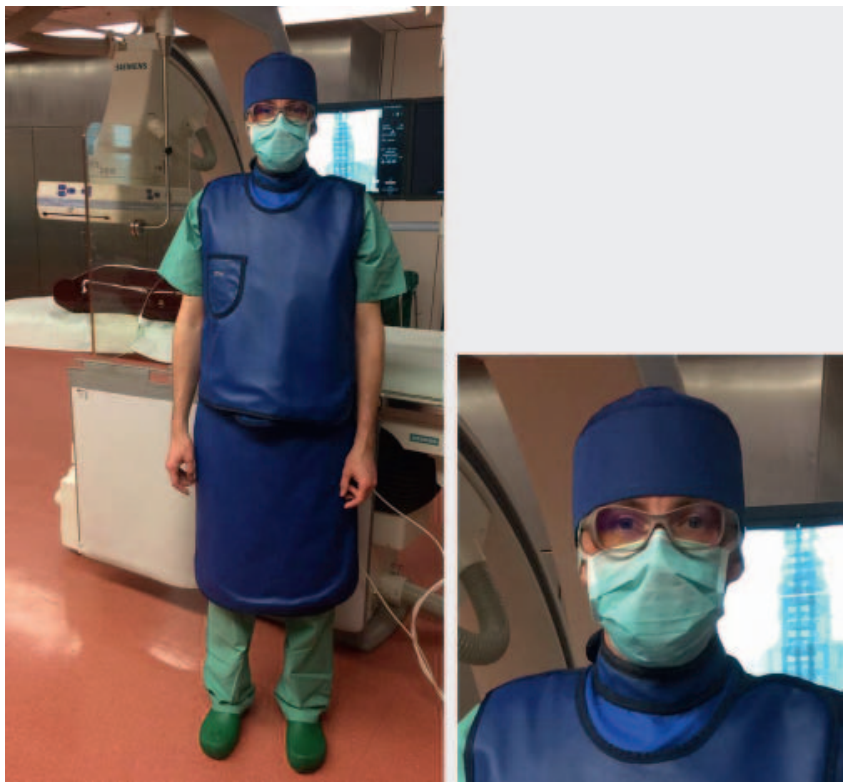

- Fig. 2 Leaded vest and skirt with thyroid protection, radiation protection glasses and radiation protection cap. The mobile lead glass screen and the under-table shielding are shown in the background.
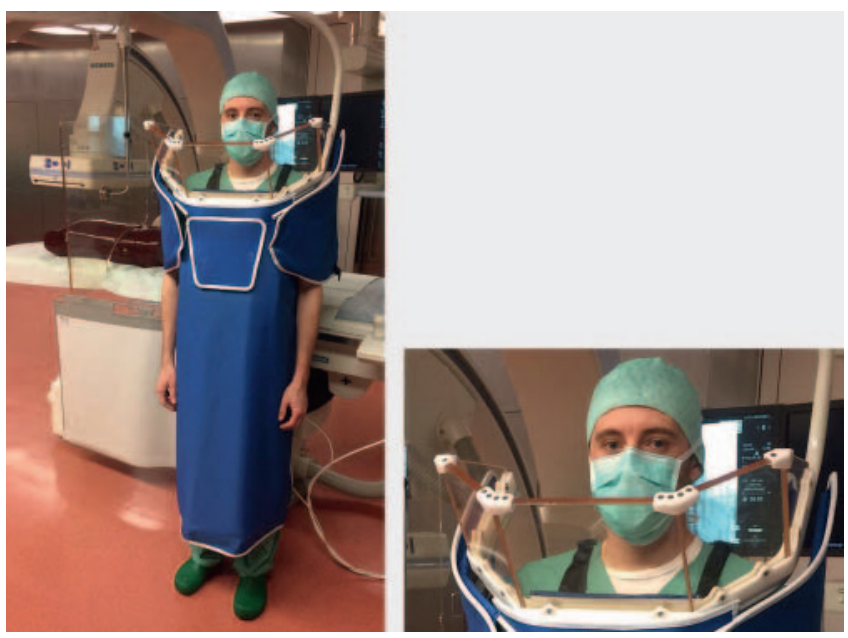

- Fig. 3 Free-hanging radiation protection system with integrated lead glass screen. The mobile lead glass screen and under-table shielding are shown in the background.

when a radiation protection barrier is used. However, this greatly limits direct access to the patient [29].

\section{Scatter radiation protection to be placed on the patient}

A further approach to reducing scatter radiation is to shield it directly at the source, namely the patient. This can range from sterile drapes coated, for example, with bismuth to lead-based radiation protection mats ( $\bullet$ Fig. 4 ). Moreover, there is a wide range of designs ranging from an extension of the mobile lead glass screen or the lateral shielding facing the examiner to complete shielding of the patient as shown in $>$ Fig. 4 . Shields made

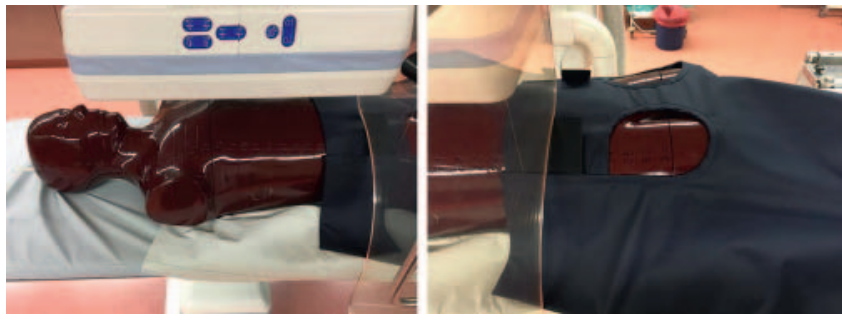

- Fig.4 Patient shielding with a femoral notch for intervention access.

of bismuth with a lead equivalent of $0.1 \mathrm{~mm}$ reduce the radiation dose up to $91 \%$ for the eyes, $96 \%$ for the thyroid, and $96 \%$ for the hands [16, 30, 31]. In their study Lange et al. were able to show an average personal dose reduction from $20.9 \mu$ Sv to $9.0 \mu$ Sv (56.9\%) by using a radiation protection mat with a lead equivalent of $0.5 \mathrm{~mm}$ on the patient [32]. However, it must be ensured that such shields are outside the primary X-ray beam when automatic dose control is activated since this would otherwise result in an increase in the radiation exposure for the patient as well as the medical staff thereby negating the benefit. Automatic dose control can usually be deactivated.

\section{Personal radiation protection for medical staff}

\section{Radiation protection apron and thyroid protection}

Conventional radiation protection for medical personnel is usually comprised of an apron that is lead-based, has reduced lead, or is lead-free, or a vest and a skirt, and thyroid protection ( $\bullet$ Fig. 2 ) with varying lead equivalents. In a survey Lynskey et al. confirmed that $99.4 \%$ of participating interventional radiologists wear a protective vest and $94 \%$ use thyroid protection [33].

In a comparison of various lead-based aprons, Toossi et al. were able to show that one-piece aprons with an overlap in the front and a lead equivalent of $0.35 \mathrm{~mm}$ (thus effectively $0.7 \mathrm{~mm}$ in the front) provide the best protection. In addition, a wraparound apron provides 5 times better radiation protection than a front apron. Thyroid protection should have a lead equivalent of $0.5 \mathrm{~mm}$ and cover a surface that is as large as possible [34]. Since lead aprons are heavy and brittle and can cause physical symptoms particularly in the back and hips [35-37] when used daily, lighter aprons made of alternative materials are available. These are usually made of a combination of bismuth, gadolinium and/ or barium sulfate and are approximately one-fourth to one-third lighter than conventional lead aprons. In a simulation, Kazempour et al. were able to show that lead aprons are most effective at energies of $40 \mathrm{kVp}$, while the combination W-Sn-Cd-EPVC provides the best protection at 60 and $90 \mathrm{kVp}$ and $\mathrm{W}-\mathrm{Sn}-\mathrm{Ba}-\mathrm{EPVC}$ at energies of $120 \mathrm{kVp}$ (Pb-lead; Si-silicon; W-tungsten; Sn-tin; Cd-cadmium; Ba-barium; EPVC-emulsion polyvinyl chloride) [38]. The absorption edges, i. e., energy ranges in which absorption increases erratically, of the various materials play a decisive role. This shows that lead and other materials are capable of ensuring adequate radiation protection with a simultaneous weight reduc- 
tion. However, the latter depends on the energy being used [39], i. e., the effectiveness of a means of radiation protection depends on the tube voltage and cannot be necessarily specified based exclusively on the lead equivalent. Therefore, there are alternative materials for thyroid protection. In their clinical studies, Uthoff et al. show that the alternative materials made of barium sulfate and bismuth oxide ensure on average the same radiation protection as lead thyroid protection. If these materials are used as a double layer, they achieve a dose reduction of $90 \%(120 \mu \mathrm{Sv}$ to $11 \mu \mathrm{Sv}$ on average) compared to no radiation protection in contrast to normal thyroid protection which provides a reduction of $72.4 \%$ (from $190 \mu$ Sv to $52 \mu$ Sv on average) [16, 40, 41].

\section{Free-hanging radiation protection system}

Another commercially available system which supports its own weight is a free-hanging radiation protection system with an integrated lead glass screen for protecting the head-neck region ( $\triangleright$ Fig.3). Multiple studies were able to show that this system ensures significantly better radiation protection particularly in the head-neck region than conventional systems [42, 43]. As an example, Savage et al. report a $94 \%$ reduction (from $2.4 \mu \mathrm{Sv} / \mathrm{min}$ to $0.14 \mu \mathrm{Sv} / \mathrm{min}$ ) in the local dose for the head-neck region compared to the conventional radiation protection system including a mobile lead glass screen and under-table protection [44].

\section{Radiation protection glasses and visors}

Multiple systems, such as protective glasses, visors and headgear, were developed to compensate for the disadvantage of conventional radiation protection particularly in the head-neck region. In particular the development of protective glasses, in part due to the new eye lens limit of $20 \mathrm{mSv}$ per year, has become increasingly important in recent years. However, the wearing of radiation protection glasses is a current topic of discussion as reflected in the study by Lynskey et al. in which only $54.2 \%$ of all surveyed radiologists stated that they wear protective glasses during an intervention [33]. Phantom experiments were able to show that the eye lens local dose can be reduced from $66.7 \%$ to $96.0 \%$ (from $0.32 \mathrm{mSv} / \mathrm{h}$ to $0.04 \mathrm{mSv} / \mathrm{h}$ as an example [18]) with a favorable X-ray tube angle and head position $[17,19]$. However, this reduction is not the same for both eyes. In their study Fetterly et al. were able to show that the eye facing away from the scatter radiation is not protected at all in an experimental test setup of an angiographic examination [45]. The main reasons for these results are the orientation of the examiner's head in relation to the source of the scatter radiation and the fit of the glasses [17]. In their clinical studies, Van Rooijen und Merce et al. show that a radiation reduction for the eye lenses of $50 \%$ can be achieved by wearing radiation protection glasses or of $82.5 \%$ when used in combination with a mobile lead glass screen $[22,46]$. It was shown that a lead equivalent of the glasses of $0.35 \mathrm{~mm}, 0.5 \mathrm{~mm}$ or greater does not result in a significant additional radiation protection effect. In the case of light models with a lead equivalent of $0.07 \mathrm{~mm}$, the radiotransparency is three times higher in relation to glasses with a lead equivalent of $0.75 \mathrm{~mm}$ [16]. Moreover, there are different models ranging from standard glasses to glasses with additional shielding on the sides to visors ( $\mathbf{F i g}$. $\mathbf{5}$ ). It was able to

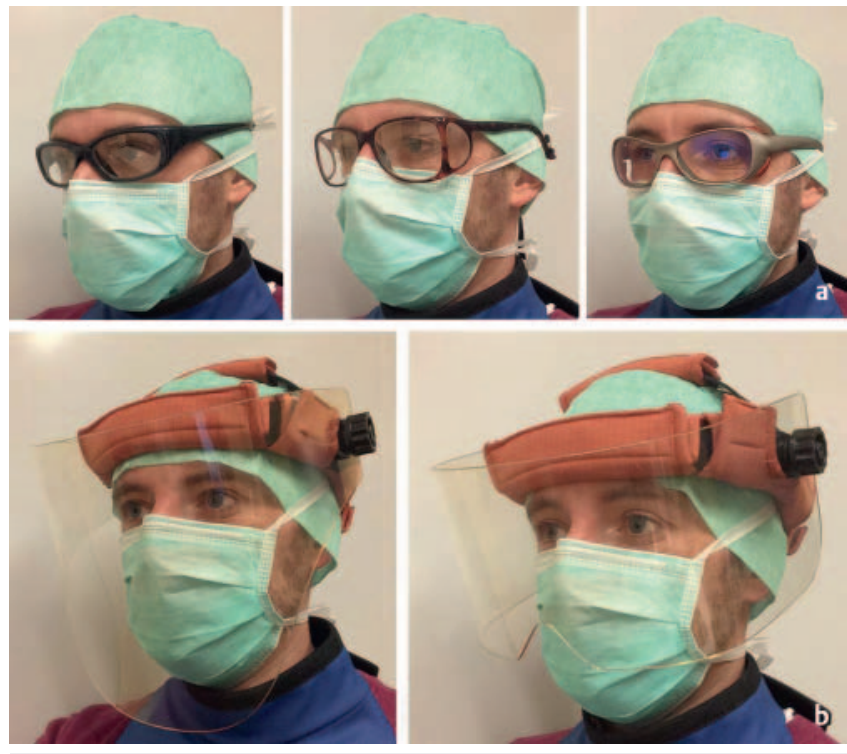

- Fig. 5 a Various radiation protection glasses. b Various radiation protection visors.

be shown that enlarging the lenses of the glasses does not affect the level of radiation protection. Only additional lateral shielding can result in further radiation protection since scatter radiation usually comes laterally from below. Galster et al. were able to show that glasses and visors achieve a lens dose reduction of approximately $85-90 \%$ [17] although visors only have a lead equivalent of $0.1 \mathrm{~mm}$ in contrast to $0.5 \mathrm{~mm}$ or even $0.75 \mathrm{~mm}$ in the case of glasses. This is because visors have a greater surface area and thus reduce the exposure of personnel to scatter radiation in the region of the head by providing better shielding ( $\vee$ Fig.5). Moreover, special radiation protection visors have the advantage that they also serve as a splash guard, particularly in the case of infectious patients.

\section{Radiation protection cap}

Current cohort studies show an incidence of increased cranial tumors in long-term radiation exposure [12]. Therefore, radiation protection of the head has again become a main focus and is a current topic of research ( $\triangleright$ Fig. 2). The equivalent dose directly beneath a radiation protection cap can be lowered on average by $85.4 \%$ (from $224 \mu \mathrm{Sv}$ to $48 \mu \mathrm{Sv}$ on average) [40]. This should also lower the eye lens organ dose since approximately $21 \%$ of eye lens radiation exposure is the result of scatter radiation from the examiner [16]. Other studies were able to show no or only a slight reduction in the equivalent dose of $3.3 \%$ for the neurocranium $[45,46]$. These measurements mainly relate to the brain surface. Therefore, there is a need for both development and research.

\section{Radiation protection gloves}

The dose limit for the hands is 500 mSv per year (directive 2013/ 59/Euratom). Since the hands are unprotected and are thus directly exposed to scatter radiation, the radiation exposure is very high here [47]. In addition, there is a risk of the hands entering the primary beam. Neeman et al. were able to show that the 
use of lead-free radiation protection gloves resulted in a reduction of the absorbed dose of $97.1 \%$ (from $1792 \mu \mathrm{Gy}$ to $52 \mu \mathrm{Gy}$ on average) in CT-guided treatments [28]. However, if the radiation protection equipment is located in the primary beam, the automatic fluoroscopy system causes the X-ray tube output and thus the radiation exposure to increase. Therefore, radiation protection for the hands is particularly difficult to implement. A current phantom study was able to show that a reduction of the equivalent dose of $42.6 \%$ can be achieved by using radiation protection gloves consisting of rubber and metal oxides (e.g. bismuth) with almost the same comfort level as conventional gloves. However, use of these gloves in the primary beam results in an increase in the equivalent dose for the hands of $64.5 \%$ [48]. To avoid this risk, tools such as needle holders are regularly used. The longer the needle holder the better the hands are protected but control of the needle decreases as the needle length increases $[49,50]$.

\section{Personal dosimetry}

\section{Dosimetry and monitoring of medical staff}

Dosimetry is intended to increase awareness of personal radiation exposure and to provide various dose limits measured and documented by the authorities for different organs and body regions. The new Radiation Protection Act requires the use of a personal identification number for the radiation protection register for persons working with ionizing radiation to ensure consistent documentation even in the case of a change of employment or name [51]. There are various options for measuring and monitoring these limit values. The film badge was one of the most widely available and most widely used systems as early as the 1960s. In 1962 the International Atomic Energy Agency published a paper regarding the use of film badges for personal monitoring. The operating principle remains unchanged and is shown in $\mathbf{F i g . 6 a}$ [52]. These dosimeters are cost-effective, highly responsive, and can be easily worn on a daily basis. The disadvantage of this system is the low accuracy at low energies and that the dose values are determined on a monthly basis so that it is not possible to draw conclusions about the cause of an increase in radiation exposure. An alternative dosimeter that has been available for approximately 10 years uses luminescent crystals (optically stimulated luminescence from beryllium oxide, BeOSL) that can be read out by optical excitation and otherwise correspond to the use of a film badge ( $\triangleright$ Fig. $\mathbf{6 b}$ ). It was able to be shown that these dosimeters have a low response at energies between 60 and $100 \mathrm{keV}$ which can however be compensated by a corresponding design and use of a linear algorithm for evaluation. Moreover, these dosimeters are also cost-effective which is due among other things to the fact that they can be read out multiple times. These dosimeters are therefore also suitable for the daily routine $[53,54]$.

\section{Electronic personal dosimeter (EPD)}

Electronic personal dosimeters (EPDs) which can display the momentary radiation exposure and optionally emit an acoustic or optical warning are available for monitoring current radiation exposure. Fig. $\mathbf{6 c}$ shows an example of an electronic personal

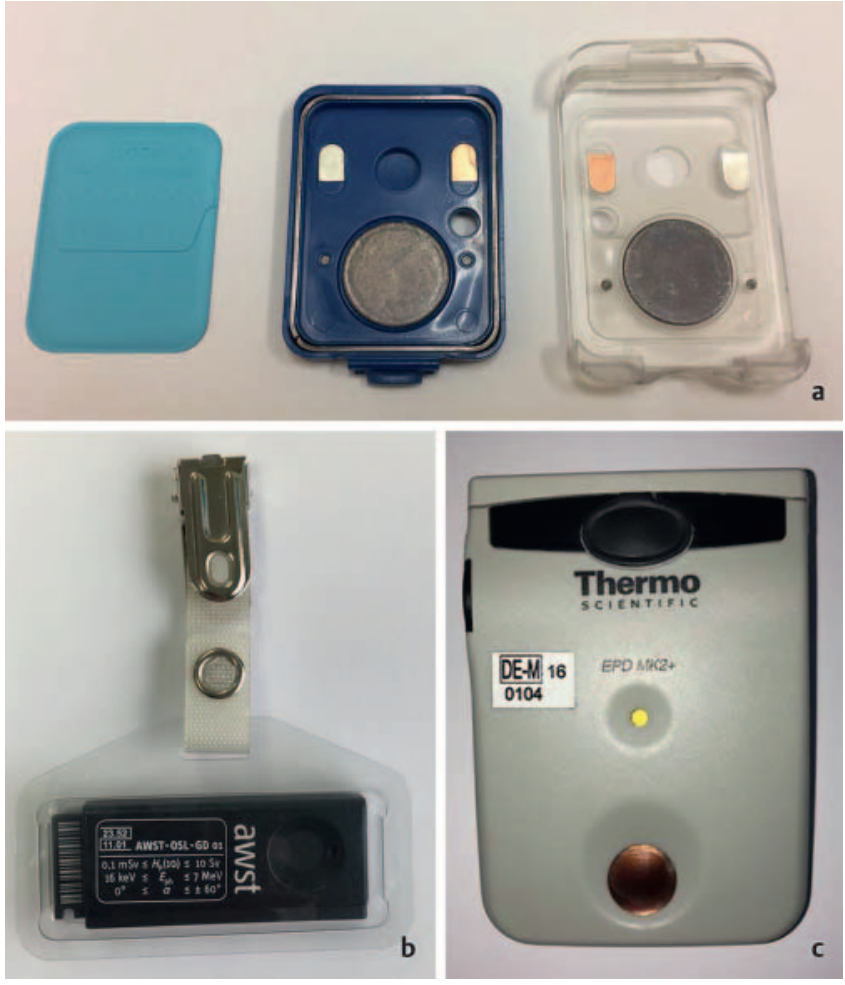

- Fig. 6 a Badge meter with various shielding materials (f.I.t.r.: X-ray film, bottom with copper and apron, cover with copper and apron). b BeOSL dosimeter. c Electronic personal dosimeter (EPD).

dosimeter. Semiconductor materials with a good sensitivity in the range between 70 and $110 \mathrm{keV}$ are used for this purpose [55]. In a study Clairand et al. compared 5 EPDs with one another and were able to show that these display correct values both at low energies and in pulsed examinations. 4 of the 5 examined dosimeters were even able to measure the local dose of an individual pulse [56]. New systems are comprised of monitoring units that can display dose values of up to 5 dosimeters at the same time. Thus, the entire medical staff can be monitored with one central monitoring unit during an examination. The advantage of this system is that every person in the examination room is measured in real time and immediate action can be take in the case of increased radiation exposure $[57,58]$. Sailer et al. were able to show in a current study that this not only increases the feeling of safety of medical personnel but also results in a significant reduction in the personal dose for technical personnel (from $0.12 \mu \mathrm{Sv} /$ Gy $\mathrm{cm}^{2}$ to $0.08 \mu \mathrm{Sv} / \mathrm{Gy} \mathrm{cm}^{2}$ ) [59].

\section{Dosimeter position}

Apart from the selection of a suitable dosimeter, the position and use play a decisive role. Rigatelli et al. were able to show that radiologists with a body size $<165 \mathrm{~cm}$ have higher dose values on their dosimeters than radiologists with a body size $>165 \mathrm{~cm}$ provided that the dosimeter is worn in the same body region. This can be explained by the distribution of scatter radiation. Therefore, it is important for dosimeters to always be worn in the same representative position, e.g. on the breast pocket [60]. As 
shown in $>$ Table 1, there are different dose limits for different organs and body regions. Since not all body regions can be measured individually, the dose for these can be estimated with the help of reference measurements. In their study Fetterly et al. use a dosimeter on the left collar and obtain an equivalent dose exposure of $8.4 \%$ of the total measured dose value for the brain, $72 \%$ for the left carotid, $28 \%$ for the right carotid, $25 \%$ for the left eye lens, and $9.2 \%$ for the right eye lens from reference measurements [45]. Neto et al. continue to recommend the use of two dosimeters, one beneath the lead apron and one on top of the apron to determine the correct body dose [61]. If individual body regions are to be measured or monitored in certain applications, special dosimeters such as the ring dosimeter for the finger as is typically used in nuclear medicine can be used.

\section{Summary and current trends}

Optimal radiation protection always includes a combination of various means of radiation protection and methods. In their study Adamus et al. show successive dose reduction with use of additional radiation protection means for the average equivalent dose for the eye lenses based on the example of TIPPS placement (transjugular intrahepatic portosystemic shunt). If only one under-table shield is used, an average eye lens dose of $466 \mathrm{mSv}$ is achieved. This value decreases to $55 \mathrm{mSv}$ when a lateral patient shield (upwardly extendable under-table shield) and a mobile lead glass screen are additionally used. A further reduction of the eye lens dose to $9.5 \mathrm{mSv}$ can be achieved by using radiation protection glasses [62].

It is mandatory to use a radiation protection apron which should cover at least $60 \%$ of the body surface according to the current DIN Standards Committee Radiology (based on IEC 61331-3:2014-05, subitem 5.4), thyroid protection and radiation protection systems mounted to the patient table or ceiling. Radiation protection of the head-neck region, particularly the eye lens, is expected to become increasingly important. However, there continues to be a need for further development primarily with respect to eye lens dose and monitoring. New radiation protection glasses with integrated dosimeters are expected here so that the exact equivalent dose can be determined and thus the cataract risk can be reduced. In general, dosimetry plays an important role and an EPD should be added to the mandatory monthly dosimeter readouts when possible in order to directly identify dose values and optimize courses of action. This major advantage was able be shown in a current study. Not only the feeling of safety of medical personnel could be increased but also the radiation exposure of medical personnel could be significantly reduced.

Therefore, the correct combination of radiation protection equipment and corresponding dosimetry increases safety when working with $\mathrm{X}$-rays.

\section{Conflict of Interest}

The authors declare that they have no conflict of interest.

\section{References}

[1] Fritz-Niggli H. Forschung mit Röntgenstrahlen, Bilanz eines Jahrhunderts; Strahlenbiologie - Von den Anfängen zur heutigen Forschung. Berlin, Heidelberg, New York: Springer Verlag; 1995: 299-315

[2] Gohrbandt E, Gebka J, Berndorfer A. Handbuch der plastischen Chirurgie. Band 1 Walter de Gruyter; 1972: 17

[3] Unna PG. Die chronische Röntgendermatitis der Radiologen. Fortschr Röntgenstr 1904-1905; 8: 67-91

[4] Levy-Dorn M. Vorrichtungen zum Schutz des Untersuchers gegen die Röntgenstrahlen. Münch Med Wschr 1898; 8: 577

[5] Levy-Dorn M. Neues aus der Röntgentechnik Verhandl. Dtsch Röntgen-Ge $1905 ; 1: 149-153$

[6] Geyer PS. Strahlenschutz und Strahlenschäden beim Umgang mit Röntgenstrahlen in der Veterinärröntgenologie; Eine Untersuchung der deutsch- und englischsprachigen Literatur unter Brücksichtigung der aktuellen Röntgenverordnung. Dissertation Freie Universität Berlin. 2003. Journal Nr. 2704

[7] Bhargavan M. Trends in the utilization of medical procedures that use ionizing radiation. Health Physics 2008; 95: 612-627

[8] Mettler FA, Bhargavan M, Faulkner K et al. Radiologic and Nuclear Medicine Studies in the United States and Worldwide: Frequency, Radiation Dose, and Comparison with Other Radiation Sources 1950-2007. Radiology 2009; 253: 520-531

[9] Kloeckner R, Santos DP, Schneider J et al. Radiation exposure in CT-guided interventions. European Journal of Radiology 2013; 82: $2253-2257$

[10] Kitahara CM, Linet MS, Balter S et al. Occupational Radiation Exposure and Deaths From Malignant Intracranial Neoplasms of the Brain and CNS in U.S. Radiologic Technologists, 1983-2012. Am J Roentgenol 2017; 208: $1-7$

[11] Linet MS, Hauptmann M, Freedman DM et al. Interventional radiography and mortality risks in U.S. radiologic technologists. Pediatr Radiol 2006; 36: $113-120$

[12] Rajaraman P, Doody MM, Yu CL et al. Cancer Risks in U.S. Radiologic Technologists Working With Fluoroscopically Guided Interventional Procedures, 1994-2008. Am J Roentgenol 2016; 206: 1101-1110

[13] Seals KF, Lee EW, Cagnon CH et al. Radiation-Induced Cataractogenesis: A Critical Literature Review for the Interventional Radiologist. Cardiovasc Intervent Radiol 2016; 39: 151 - 160

[14] Vano E, Gonzalez L, Beneytez $F$ et al. Lens injuries induced by occupational exposure in non-optimized interventional radiology laboratories. The British Journal of Radiology 1998; 71: 728-733

[15] Luchs JS, Rosioreanu A, Gregorius D et al. Radiation Safety during Spine Interventions. J Vasc Interv Radiol 2005; 16: 107-111

[16] Meisinger QC, Stahl CM, Andre MP et al. Radiation Protection for the Fluoroscopy Operator and Staff. Am J Roentgenol 2016; 207: 745-754

[17] Galster M, Guhl C, Uder M et al. Exposition der Augenlinse des Untersuchers und Effizienz der Strahlenschutzmittel bei fluoroskopischen Interventionen. Fortschr Röntgenstr 2013; 185: 474-481

[18] Thornton RH, Dauer LT, Altamirano JP et al. Comparing Strategies for Operator Eye Protection in the Interventional Radiology Suite. J Vasc Interv Radiol 2010; 21: 1703-1707

[19] Hu P, Kong Y, Chen B et al. Shielding effect of lead glasses in radiologists eye lens exposure in interventional procedures. Radiation Protection Dosimetry 2017; 174: 136-140

[20] Vanhavere F, Carinou E, Domienik J et al. Measurements of eye lens doses in interventional radiology and cardiology: Final results of the ORAMED project. Radiation Measurements 2011; 46: 1243-1247 
[21] Martin C]. Eye lens dosimetry for fluoroscopically guided clinical procedures: practical approaches to protection and dose monitoring. Radiat Prot Dosimetry 2016; 169: 286-291

[22] Van Rooijen BD, De Haan MW, Das M et al. Efficacy of Radiation Safety Glasses in Interventional Radiology. Cardiovasc Intervent Radiol 2014; 37: $1149-1155$

[23] Maeder M, Brunner-La Rocca HP, Wolber T et al. Impact of a Lead Glass Screen on Scatter Radiation to Eyes and Hands in Interventional Cardiologists. Catheterization and Cardiovascular Interventions 2006; 67: 18-23

[24] Gilligan P, Lynch J, Eder H et al. Assessment of Clinical Occupational Dose Reduction Effect of a New Interventional Cardiology Shield for Radial Access Combined With a Scatter Reducing Drape. Catheterization and Cardiovascular Interventions 2015; 86: 935-940

[25] Schueler A, Vrieze TJ, Bjarnason $\mathrm{H}$ et al. An Investigation of Operator Exposure in Interventional Radiology. RadioGraphics 2006; 26: 1533-1541

[26] Shortt CP, Al-Hashimi H, Malone L et al. Staff Radiation Doses to the Lower Extremities in Interventional Radiology. Cardiovasc Intervent Radiol 2007; 30: 1206 - 1209

[27] Mahnken AH, Sedlmair M, Ritter C et al. Efficacy of Lower-Body Shielding in Computed Tomography Fluoroscopy-Guided Interventions. Cardiovasc Intervent Radiol 2012; 35: 1475-1479

[28] Neeman Z, Dromi SA, Sarin S et al. CT Fluoroscopy Shielding: Decreases in Scattered Radiation for the Patient and Operator. J Vasc Interv Radiol 2006; 17: 1999-2004

[29] Haipt F, Kirsch M, Hosten N. Evaluation einer Strahlenschutzwand als Dauerschutzeinrichtung zur Dosisreduktion des Arztes bei Interventionen unter CT-Durchleuchtung. Fortschr Röntgenstr 2010; 182: 512 517

[30] King JN, Champlin AM, Kelsey CA et al. Using a Sterile Disposable Protective Surgical Drape for Reduction of Radiation Exposure to Interventionalists. Am J Roentgenol 2002; 178: 153-157

[31] Dromi S, Wood B], Oberoi J et al. Heavy Metal Pad Shielding during Fluoroscopic Interventions. J Vasc Interv Radiol 2006; 17: 1201 - 1206

[32] Lange HW, von Boetticher H. Reduction of Operator Radiation Dose by a Pelvic Lead Shield During Cardiac Catheterization by Radial Access. JACC 2012; 5: $445-449$

[33] Lynskey GE, Powell DK, Dixon RG et al. Radiation Protection in Interventional Radiology. J Vasc Interv Radiol 2013; 24: 1547-1551

[34] Toossi MTB, Zare H, Bayani SH et al. Evaluation of the Effectiveness of the Lead Aprons and Thyroid Shields Worn by Cardiologists in Angiography Departments of Two Main General Hospitals in Mashhad, Iran. Journal of Nuclear Science and Technology 2008; 5: 159-162

[35] Andreassi MG, Piccaluga E, Guagliumi G et al. Occupational Health Risks in Cardiac Catheterization Laboratory Workers. Circ Cardiovasc Interv 2016; 9: 1-8

[36] Klein LW, Tra Y, Garratt KN et al. Occupational Health Hazards of Interventional Cardiologists in the Current Decade. Catheterization and Cardiovascular Interventions 2015; 86: 913-924

[37] Goldsein JA, Balter S, Cowley M et al. Occupational Hazards of Interventional Cardiologists: Prevalence of Orthopedic Health Problems in Contemporary Practice. Catheterization and Cardiovascular Interventions 2004; 63: 407-411

[38] Kazempour M, Saeedimoghadam M, Shekoohi Shooli F et al. Assessment of the Radiation Attenuation Properties if Several Lead Free Composites by Monte Carlo Simulation. J Biomed Phys Eng 2015; 5: 67-76

[39] McCaffrey JP, Tessier F, Shen H. Radiation shielding materials and radiation scatter effects for interventional radiology (IR) physicians. Med Phys 2012; 39: 4537-4546

[40] Uthoff H, Pena C, West J et al. Evaluation of Novel Disposable, LightWeight Radiation Protection Devices in an Interventional Radiology Setting: A Randomized Controlled Trial. Am J Roentgenol 2013; 200: 915-920
[41] Uthoff H, Benenati M], Katzen BT et al. Lightweight Bilayer Barium Sulfate-Bismuth Oxide Composite Thyroid Collars for Superior Radiation Protection in Fluoroscopy-guided Interventions: A Prospective Randomized Controlled Trial. Radiology 2014; 270: 601-606

[42] Marichal DA, Anwar T, Kirsch D et al. Comparison of a Suspended Radiation Protection System versus Standard Lead Apron for Radiation Exposure of a Simulated Interventionalist. J Vasc Interv Radiol 2011; 22: 437-442

[43] Haussen DC, Van Der Bom IM], Nogueira RG. A prospective case control comparison of the ZeroGravity system versus a standard lead apron as radiation protection strategy in neuroendovascular procedures. I Neurolntervent Surg 2016; 8: $1052-1055$

[44] Savage C, Seale TM, Shaw C] et al. Evaluation of a Suspended Personal Radiation Protection System vs. Conventional Apron and Shields in Clinical Interventional Procedures. Open Journal of radiology 2013; 3: $143-151$

[45] Fetterly K, Schueler B, Grams M et al. Head and Neck Radiation Dose and Radiation Safety for Interventional Physicians. Cardiovascular interventions 2016; 10: 520-528

[46] Merce MS, Korchi AM, Kobzeva L et al. The value of protective head cap and glasses in neurointerventional radiology. J Neurolntervent Surg 2016; 8: $736-740$

[47] Sakamoto H, Ikegawa H, Kobayashi $\mathrm{H}$ et al. A study of operator's hand and finger exposure dose reduction during angiographic procedures. Nihon Hoshasen Gijutsu Gakkai Zasshi 2009; 65: 25-34

[48] Kamusella P, Scheer F, Lüdke CW et al. Interventional Angiography: Radiation Protection for the Examiner by using Lead-free Gloves. Journal of Clinical and Diagnostic Research 2017; 11: 26 -29

[49] Stoeckelhuber BM, Leibecke T, Schulz E et al. Radiation Dose to the Radiologist's Hand During Continuous CT Fluoroscopy-Guided Interventions. Cardiovasc Intervent Radiol 2005; 28: 589-594

[50] Sarmento S, Pereira JS, Sousa M] et al. The use of needle holders in CTF guided biopsies as a dose reduction tool. J Appl Clin Med Phys 2018; 19 : $250-258$

[51] Wigge P. Das neue Strahlenschutzgesetzgesetz - Überblick über die Auswirkungen auf das Fachgebiet der Radiologie. Fortschr Röntgenstr 2017; 189: 1010-1014

[52] The Use of Film Badges for Personal Monitoring. Vienna: International Atomic Energy Agency. 1962. (Safety Series No. 8)

[53] Jahn A, Sommer M, Henniger ]. Environmental Dosimetry with the BeOSL Personal Dosemeter. Radiation Protection Dosimetry 2016; 170: 346 349

[54] Haninger T, Hödlmoser H, Figel M et al. Properties of the BeOSL Dosimetry system in the framework of a large-scale personal monitoring service. Radiation Protection Dosimetry 2016; 170: 269-273

[55] Terasaki K, Fujibuchi T, Murazaki H et al. Evaluation of basic characteristics of a semiconductor detector for personal radiation dose monitoring. Radiol Phys Technol 2017; 10: 189-194

[56] Clairand I, Struelens L, Bordy JM et al. Intercomparison of active personal dosemeters in interventional radiology. Radiation Protection Dosimetry 2008; 129: 340 - 345

[57] Cardoso J, Santos JAM, Santos L et al. Characterization of an active dosemeter according to IEC 61526:2010. Radiation Protection Dosimetry 2016; 170: 127-131

[58] Mangiarotti M, D’Ercole L, Quaretti P et al. evaluation ofan active personal dosimetry system in interventional radiology and neuroradiology: preliminary results. Radiation Protection Dosimetry 2016; 172: 483-487

[59] Sailer AM, Vergoossen L, Paulis L et al. Personalized Feedback on Staff Dose in Fluoroscopy-Guided Interventions: A New Era in Radiation Dose Monitoring. Cardiovasc Intervent Radiol 2017; 40: 1756-1762 
[60] Rigatelli G, Panin S, Fiorrevanti R et al. Impact of Operators' Height on Individual Radiation Exposure Measurements During Catheter-Based Cardiovascular Interventions. Journal of Interventional Cardiology 2016; 29: $83-88$

[61] Neto FAB, Alves AFF, Mascarenhas YM et al. Efficiency of personal dosimetry methods in vascular interventional radiology. Physica Medica 2017; 37: $58-67$
[62] Adamus R, Loose R, Wucherer $M$ et al. Strahlenschutz in der interventionellen Radiologie. Radiologe 2016; 56: 275-281 